УДК 004.75

DOI: $10.15827 / 2311-6749.17 .4 .8$

\title{
ВАРИАНТ ПОСТРОЕНИЯ ЭКСПЕРТНОЙ СИСТЕМЫ ФОРМИРОВАНИЯ ОБАИКА ГЕОИНФОРМАЦИОННОЙ СИСТЕМЫ МОРСКОГО СУДНА
}

\author{
П.И. Смирнов, к.т.н., доиент, p.smirnov@mashtab.org \\ (Санкт-Петербургский национальный исследовательский университет информаиионных \\ технологий, механики и оптики, просп. Кронверкский, 49, г. Санкт-Петербург, 197101, Россия); \\ T.M. Татарникова, д.т.н., доиент, профессор, tm-tatarn@yandex.ru \\ (Санкт-Петербургский государственный университет аэрокосмического приборостроения, \\ ул. Большая Морская, 67а, г. Санкт-Петербург, 1900о0, Россия); \\ Н.В. Яготиниева, старший преподаватель \\ (Российский государственный гидрометеорологический университет, просп. Малоохтинский, 98, \\ 2. Санкт-Петербург, 195196, Россия)
}

\begin{abstract}
Предлагается концептуальная модель геоинформационной системы морского судна. Модель отличается описанием иерархии компонентов, поддерживающих функциональность геоинформационной системы, их производительностью, стоимостью и занимаемой площадью. Количественное представление модели с качественными характеристиками ее функциональных модулей позволяет выполнить структурную оптимизацию геоинформационной системы принятия решения при управлении судном под цели плавания. Предлагается экспертная система, автоматизирующая приближение архитектуры геоинформационной системы к заданному набору свойств, задающих качество ее функционирования. В диалоговом режиме экспертная система формирует списочный состав функциональных модулей и оборудования, необходимого при проектировании геоинформационной системы морского судна.

Ключевые слова: геоинформационная система, количественные и качественные характеристики ГИС, оптимальная архитектура ГИС, автоматизащия выбора оптимальной архитектуры ГИС, экспертная система выбора архитектуры ГИС.

Применение геоинформационных систем (ГИС) в управлении динамическими объектами является сложной комплексной задачей, требующей привлечения специальных математических моделей, методик и программно-аппаратных средств реализации ГИС. Эта задача становится особенно актуальной применительно к управлению морскими судами, поскольку возникает необходимость в реальном масштабе времени получать информацию о местоположении, окружающей обстановке, метеорологических условиях, рассчитать загрузку пути, время прибытия и на основе этих данных принимать решение о прокладке и корректировке маршрута [1].

Анализ публикаций и нормативных документов за последние 5-7 лет относительно вопросов технической реализации задач управления морскими судами показал, что это направление развивается в сторону интеграции существующих комплексов, станций, систем и функциональных элементов в единую ГИС морского судна, построенную на технологии локальной сети с коммутацией сегментов [2].

С другой стороны, реализация ГИС поддержки принятия решения при управлении морским судном связана с рядом проблем, таких как необходимость оперировать большими объемами разнородных геоданных, поступающих от разных источников и зачастую в несовместимых форматах, стесненность площади для реализации инфраструктуры ГИС на судне, отсутствие комплексного подхода к проектированию подобных ГИС с учетом существующих ограничений на ее производительность и надежность [3].
\end{abstract}

\section{Концептуальная модель ГИС морского судна}

Концептуальную модель ГИС морского судна можно представить в виде трехслойной структуры: внутренний слой - информационное обеспечение, средний - программное обеспечение, внешний - аппаратное обеспечение.

Информационное обеспечение ГИС морского судна определяют картографические данные и данные, необходимые для управления судном, вместе они образуют электронные картографические навигаиионные информационные системы (ЭКНИС).

Программное обеспечение реализует функциональные возможности ГИС и состоит из базового программного обеспечения, такого как операционные системы, системы управления БД, системы визуализации данных и других, и прикладного программного обеспечения, предназначенного для решения специализированных задач судовождения, обработки сигналов, обработки и передачи данных и т.д.

Аппаратный слой ГИС представлен шестью функииональными модулями (ФМ), состоящими из устройств и средств, реализующих соответствующую функцию (рис. 1). 
Транспортной основой распределенной ГИС является локальная вычислительная сеть с коммутацией сегментов, технология построения которой позволяет одновременно передавать данные между всеми взаимодействующими парами «клиент-сервер» [4-6].

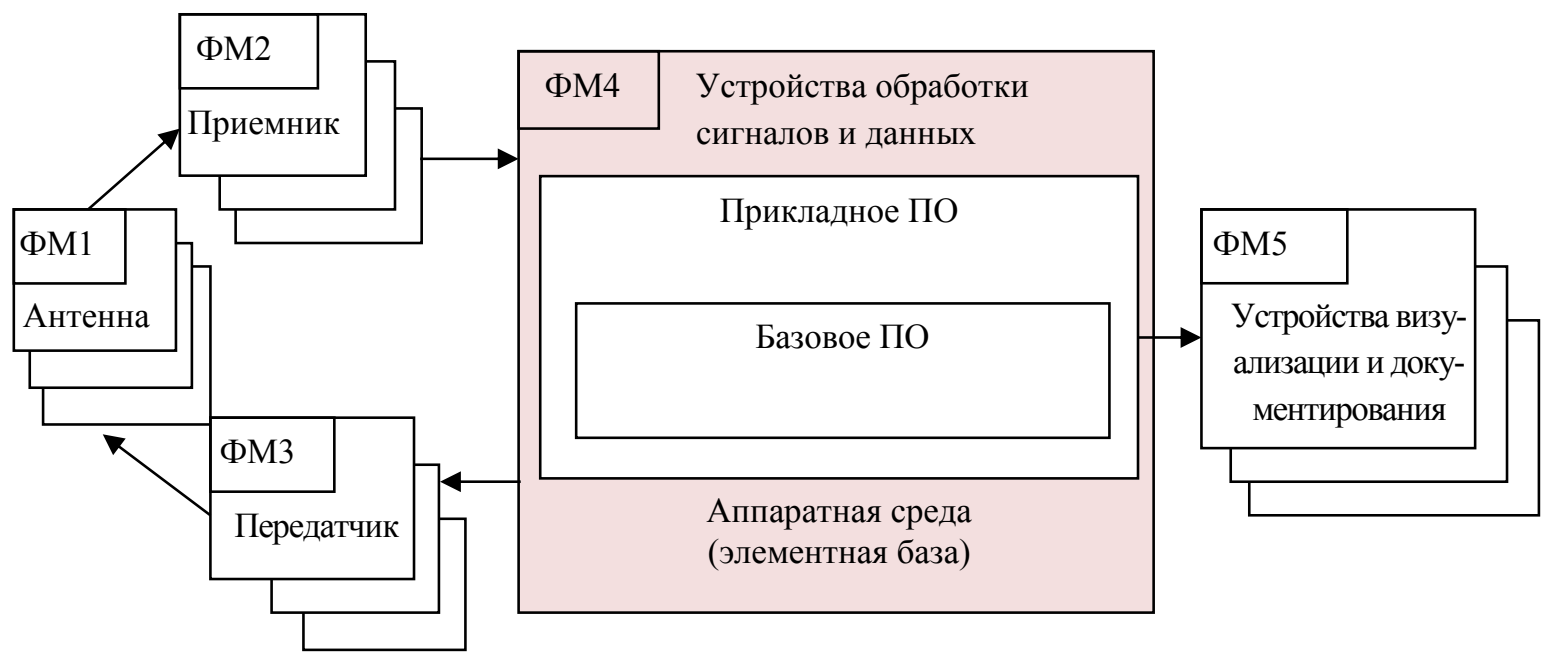

Рис. 1. Модель аппаратного обеспечения ГИС морского судна

Представим модель ГИС морского судна количественно в следующем виде:

$G=f(P, C, S)$,

где $G$ - структурно-функциональная модель ГИС морского судна; $P$ - множество параметров, которые задаются как технические требования на функциональные модули ГИС; $C$ - множество стоимостных характеристик функциональных модулей ГИС; $S$ - множество пространственных параметров (формфакторов) функциональных модулей ГИС.

\section{Постановка задачи}

Задачу исследования сформулируем как задачу разработки методического обеспечения для проектирования облика ГИС морского судна под заданные цели плавания и с учетом ограничений на требуемые показатели производительности ГИС при работе с актуальными данными.

Выбор облика ГИС решается как целочисленная задача условной многопараметрической оптимизации с ограничениями второго рода по стоимости, производительности и ограничений на площади, выделяемые под проект ГИС:

$$
C \rightarrow \min _{P},
$$

где $C$ - стоимость ГИС, которая является аддитивной функцией стоимостных характеристик ее составных элементов;

$\bar{t}_{\text {дост }}(G) \leq T_{\text {доп }}$

где $\bar{t}_{\text {дост }}(G)$ - среднее время доставки данных клиенту ГИС; $T_{\text {доп }}$ - ограничения на время доставки, рекомендуемые стандартами распространения пространственных данных;

$$
S \leq S_{\text {доп }}
$$

где $S_{\text {доп }}$ ограничения на выделяемые площади под ГИС на судне.

Последовательность действий для приближения архитектуры ГИС к заданному набору свойств (1)-(4) автоматизирована и представляет собой экспертную систему, описание которой приведено ниже.

\section{Особенности реализации экспертной системы}

Выбор варианта инфраструктурного решения построения ГИС основан на сценарном подходе, согласно которому поиск решения идет от исходных данных к целевому параметру.

Экспертная система построена по модульному принципу и состоит из следующих компонентов: рабочая память (БД, Б3), решатель, подсистемы приобретения знаний, объяснения и диалог.

БД состоит из набора таблиц, хранящих данные о навигационном оборудовании, наличие которого определено в требованиях ГМССБ, компонентах для формирования сети и наиболее важных компонентах APM. 
БЗ определяет правила работы экспертной системы и имеет следующую логическую структуру:

- для определения количества АРМ:

если $\langle$ категория судна $\rangle=\langle$ наименование», то $\langle$ количество АРМ $\rangle=n$;

- для определения количества узлов и времени доставки данных до приемника:

если $\langle$ морской район $\rangle=A_{i}, i=\overline{1,4}$, то $\langle$ количество узлов без АРМ $\rangle=N,\langle$ время доставки $\rangle=t_{\text {дост }}$;

- для определения сценариев:

если $\left\langle\bar{t}_{\text {дост }} \leq T_{\text {доп }}\right\rangle$, то $\langle$ вывести полный списочный состав аппаратного слоя ГИС $\rangle$ [7-9];

если 〈в списочном составе больше одного наименования в категориях $\rangle$, то оптимизировать по цене.

Исходя из определения типа судна и морского района плавания решатель определяет количество узлов ГИС и оценивает время доставки данных до системы с целью определения ограничений.

Интерфейс экспертной системы предусматривает ввод исходных данных в режиме диалога, выбор района плавания, границы которого визуализируются на карте, выход на решатель и БД (рис. 2).



Рис. 2. Интерфейс экспертной системь 
Экспертная система доступна для обновления информации, пополнения новыми правилами, расширения рабочей памяти.

\section{Заключение}

Предложенная концептуальная модель ГИС морского судна отличается описанием иерархии компонентов, поддерживающих функциональность ГИС, что позволяет выполнить структурную оптимизацию ГИС принятия решения при управлении судном под цели плавания.

Для решения задачи формирования инфраструктуры ГИС поддержки принятия решения при управлении морским судном предложены архитектура ГИС и последовательность действий для приближения этой архитектуры к заданному набору свойств.

Выбор облика ГИС морского судна реализован в виде экспертной системы, автоматизирующей последовательность проектирования ГИС морского судна. Экспертная система позволяет в диалоговом режиме формировать списочный состав функциональных модулей и оборудования ГИС. На основе логики, прописанной в Б3, реализовано взаимодействие решателя с рабочей памятью экспертной системы и применение математических моделей по оценке производительности проектируемой ГИС.

\section{Лuтература}

1. Бурханов М.В., Малкин И.М. Навигация с ЭКНИС. М.: Моркнига, 2014. 298 с.

2. Татарникова Т.М., Яготинцева Н.В. Характеристика проблемы интеграции образцов радиоэлектронного вооружения корабля // Ученые записки РГГМУ. 2012. № 25. С 156-162.

3. Tatarnikova T., Kolbanev M. Statement of a task corporate information networks interface centers structural synthesis. IEEE EUROCON, 2009, St. Petersburg, 2009, pp. 1883-1887.

4. Тоненбаум Э., Остин Т. Архитектура компьютера. СПб: Питер, 2013. 520 с.

5. Tanenbaum A., Wetherall D. Computer Networks. Prentice Hall Pabl., 2010, 5th ed., 960 p.

6. Олифер В., Олифер Н. Компьютерные сети. Принципы, технологии, протоколы. СПб: Питер, 2016. 992 c.

7. Кутузов О.И., Татарникова Т.М. Моделирование систем и сетей телекоммуникаций. СПб: Изд-во РГГМУ, 2012. 134 с.

8. Богатырев В.А., Богатырев С.В. Резервированная передача данных через агрегированные каналы в сети реального времени // Изв. вузов: Приборостроение. 2016. Т. 59. № 9. С. 735-740.

9. Смирнов П.И., Шустров А.К. Современные тенденции в области управления телекоммуникациями // Новые информационные технологии в системах связи и управления. 2013. С. 26-30. 